\title{
The Management Education based on Online Informal Learning Technology
}

\author{
C.L Wen \\ School of Business, Changzhou University, Changzhou, China
}

\begin{abstract}
Information is an essential element in the decision- making processes, and, from a theoretical point of view, the more useful the available information is, the easier decision making becomes. Information and Communication Technologies (ICTs), which are now commonplace in everyday activities, can generate a vast amount of information. Only a part of this information, however, is truly meaningful and useful within organizations. Data mining or information visualization techniques may solve the problem of accessing valuable data, but the application of such techniques in every possible context verges on impossible. Recently, the information technology is an important aspect of the learner's learning process. E- Learning method using the information technology impact on inevitable methods of teaching and learning process. The new trend, in the case of information technology based learning and teaching, includes: thinking, reading, listening, speaking, a useful method to effective teaching and learning, and information, communication, and computer based method using computer means and information technologies. In the proposed work, a new web based method for HPM using computers with automatically education managed components is proposed. The proposed method uses the basic HPM framework to process I/O components and different applications. The proposed method has two aspects: local education management component and global education management component. The local education management component uses the model-free computer aided learning technique to perform local education management. Moreover, global education management component interacts with the CPU processer to perform effective global education management.
\end{abstract}

KEYWORD: Management education, online technology, information technology

\section{INTRODUCTION}

Information is an essential element in the decisionmaking processes, and, from a theoretical point of view, the more useful the available information is, the easier decision making becomes. Information and Communication Technologies (ICTs), which are now commonplace in everyday activities, can generate a vast amount of information. Only a part of this information, however, is truly meaningful and useful within organizations. Data mining or information visualization techniques may solve the problem of accessing valuable data, but the application of such techniques in every possible context verges on impossible. Making business decisions on the basis of employees' in formal learning activities is an especially complex case. This complexity a rises from the need for not only a technological effort to gather the informal learning activities, but also a discussion between the process stakeholders - employees and decision makers- about how to evaluate and take into account the informal learning evidence.

Recently, the information technology is an important aspect of the learner's learning process. ELearning method using the information technology impact on inevitable methods of teaching and learning process. The new trend, in the case of information technology based learning and teaching, includes: thinking, reading, listening, speaking, a useful method to effective teaching and learning, and information, communication, and computer based method using computer means and information technologies. E-learning environment based teaching and learning impact on the ability to teach and learn. The ability to teach and learn using information technology is the most important method to bridge the gap between the teacher and the learner, two main components in the classroom. E-learning gives different components for teachers and learners with interactive, dynamic, effective access to a large number of information (text, graphics, and 
animation) as well as to teaching and learning in web based learning and teaching.

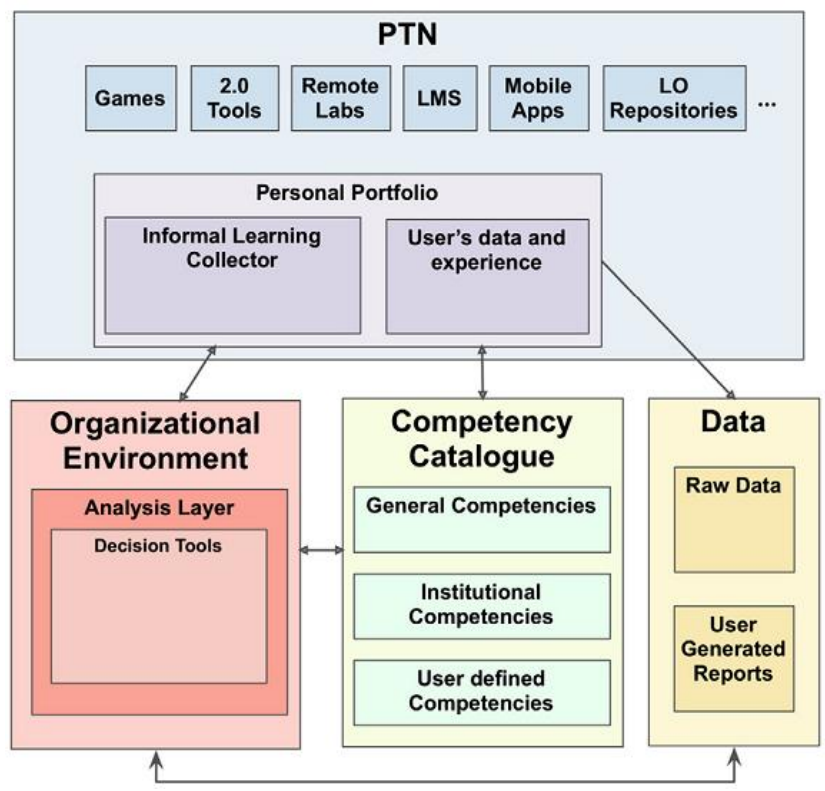

Figure 1. Research framework

An effective method of developing personal profile is called informal learning. Since learners learn in different environments, including their communications with other learners, their needs, and so forth. Informal learning is far from being a new concept. Recently, several definitions emerge, with yet more appearing at the turn of the century. Today, informal learning is again becoming the center of discussion for some reasons. First, the learning and teaching process recognizes informal learning is an important learning method. Second, a necessity to apply learning from observation and experience exists. Third, the development of the web, mobile network, and Web 3.0 tools facilitates informal learning. The recognition of in formal learning in the workplace is especially relevant, on account of a number of factors. For example, informal learning enhances employability and produces positive benefits for managers and companies. Moreover, informal learning is used to create learning and teaching skills and knowledge, and to interact social learning and teaching method of behavior.

In the proposed work, a new web based method for HPM using computers with automatically education managed components is proposed. The proposed method uses the basic HPM framework to process I/O components and different applications. The proposed method has two aspects: local education management component and global education management component. The local education management component uses the modelfree computer aided learning technique to perform local education management. Moreover, global education management component interacts with the CPU processer to perform effective global education management.

\section{THE RELATED WORK}

Comparing with the basic views given earlier of using computer aided teaching and learning method, the survey of using information based technologies for teaching and learning is given in the formal paper [1]. In the different way, different method does not seem to achieve reconciliation with the strengths of traditional explicit project knowledge [2]. Furthermore, the issue of continuous knowledge formation as a response to knowledge uncertainty in complex projects is not adequately addressed in the literature [3]. The sensing making based method and technology, the temporary organizing and learning is discussed as a complex project as a knowledge formation process for innovating solutions [4]. This method is introduced by 'effectively learning' and idea of organizing learning as interplay between 'knowledge' and 'knowing' [5]. The paper think that the given method represents a synthesis of the two main knowledge perspectives in project research explicit'known , knowledge and experiential 'knowing' knowledge [6]. According to the paper by Tjosvold et al. [7], learning from mistakes means knowing effects and reflecting on results of actions so as to low the possibilities of their future occurrence. Similarly, Hirak et al. [8], thought that "learning from failures occurs when unit members reflect on a failed experience, openly discuss why it occurred, and identify the work patterns that need be modified or changed in order to eliminate the root cause of the problem". Argote and Miron-Spektor [9] propose in this regard that the processes of knowledge acquisition, knowledge sharing and knowledge combination are central, while Edmondson claims that organizational learning is a process of change and improvement in organizational actions through better knowledge and understanding.

\section{METHODOLOGY AND ONLINE SYSTEM}

In order to make decisions on the basis of informal learning, the employee must first identify the learning, and then the organization must recognize this learning. This process takes place through a dialog between the employee and the organization. The identification of learning by employees implies the need to consider the set of tools that they use to carry out the informal learning activities that lead to this learning. These tools are related not only to an employee training platform but also to the tools the employees use in their everyday life to learn and manage knowledge. The issues that this type of learning raises are similar to those in the discourse surrounding the concept of a Personal Learning Environment (PLE) or Personal Training Environment (PTE). PTEs facilitate the user training 
process by allowing users to use the tools they want, freeing them from the constraints of a specific institutional context or training schedule. A variation of this model is the PKN, the personal online networks that allow the management of tacit and explicit knowledge. Moreover, the identification of informal learning also implies a need to store and classify the informal evidence. A portfolio system, as a place to store and manage knowledge, provides a possible solution to this problem. A competencybased model to classify the evidence performs a similar function, and the European Union and other organizations recommend this technique, which stresses the commitment to recognizing competencies and informal learning. When the identification process finishes, the organization should be able to recognize the informal evidence that the employees identify. This mechanism requires being able to process the information that the employees release to the PT N. To address this requirement, this study proposes a methodology on the basis of a technological frame-work. The methodology consists of a framework with several different components and interfaces to meet requirements of a certain level and type of interaction. Fig. 1 outlines the framework. The PTN groups the tools that users interact with in their informal learning. Some examples of these tools include Wikipedia, YouTube, games, social networks, LMS, Remote Labs, expert forums, and microblogging sites. One of the tools in the PTN is the TRAILER portfolio, which stores and publishes informal, non-formal, and formal learning experiences. The portfolio has an interface to facilitate the gathering of informal learning activities. This interface is the Informal Learning Collector (ILC). In addition, the framework contains several organizational tools. The first is a competency catalog that facilitates the categorization of informal learning experiences, taking into account both trainee and organizational perspectives. The second is an organizational environment that enables the analysis of the published information, gives support to the dialog with employees concerning their informal learning, and facilitates organizational agents' decision making to do with organizationwide training issues (e .g., in internal and external certification processes). Finally, the framework boasts a repository that stores the information for future analysis, and has reporting capabilities to generate useful reports for both the organization and employees. In this framework, the TRAILER project defines a methodology to make informal learning experiences transparent to workers and organizations in such a way that both parties benefit. The starting point of the TRAILER methodology is the moment when the user performs an online activity that may have an impact on a competency featuring in the competency catalog. The employee may then identify and match an activity with the set of possible competencies from the catalog, or store a new competency for later identification.

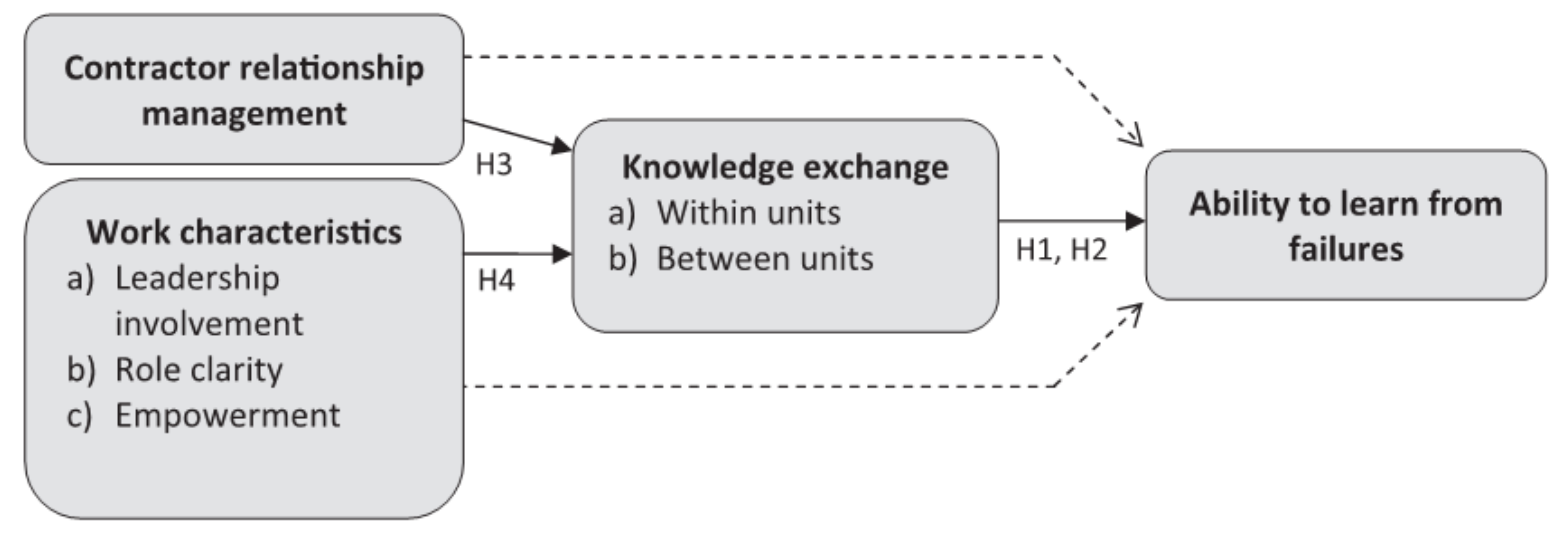

Figure 2. Research model with hypotheses

Once the system stores the information about the informal learning activity, the user can complement these details with information about associated competencies or classify the competency by using the catalog. In addition, the user can organize the information in the portfolio into different categories or views. When users organize the information properly, they can publish this material by giving the organization access. The employee can decide what to publish and who has access to that information. This information allows organizations to perform analysis on competencies, and permits workers to find peers with similar interests. The published information, once available, is suitable for making decisions about the training needs of workers, including the organization's tools and contents, and the specific skills each user has, at both the individual and group level $\mathrm{s}$. The published in format ion and the portfolio views enable a common analysis of the information that can serve as a starting point for a dialog between stakeholders. The system, once analysis is complete, can give recommendations regarding organizational skills, knowledge gaps, or personal recommendations for the learner employee. 
According to the proposed methodology and framework which is shown in Fig. 2, the Decision Support System (DSS) is a key component, comprising an analysis layer and a set of decision tools. The analysis layer is in charge of gathering the information that the workers publish to the portfolios, as well as facilitating a preliminary analysis of the data to allow for presentation of this information. The analysis layer accesses the data through two interfaces. One of these interfaces is an interface to the portfolio, called Personal Portfolio View, which gives information about the informal activities and competencies that the employee publishes. The competency catalog implements the other interface, which provides information about the competencies. A description of the information these two interfaces provide appears below.

Informal Learning Activities (ILAs) gathered by each user or the organization, including specific information about the activity (URL, title, content, comments) and the competencies associated with the activity. Information about competencies associated with a user or the organization. This information includes data such as the ID in the catalog, if the competency has links to an ILA, and to which ILA, the corresponding working areas, most recent date of access or use, and so forth. Information about the nature of the relationship between the users and the organization. Information about competencies, working areas and tags, which includes competency names, tags, corresponding working areas, types of competencies (general, organizational , userdefined), whether the competency needs validations, and so forth. All this information is suitable for decision making at the personal and organizational levels. To simplify the process, however, showing this information in a more convenient format for managers and other agents involved in decision making is helpful. To this end, the information comes in several possible formats.

\section{DISCUSSIONS}

In this section, the results on the above experiment of the proposed method show the ability of using the proposed method on managing learning and teaching, and thus try to give the evaluation of the proposed method. The results illustrate that that knowledge transfer between components is the core in learning and teaching systems. The reason of this result may be blamed to the importance of diversity of views and perspectives so as to create and maintain the effectiveness in the learning and teaching system. Following to results, the learning and teaching system facing disadvantage and problems of five focuses on active problems other than trying to mine deeper and clearer latent conditions. However, there is relation between technology and research complexity, and diversity according to problems will therefore face organizations to avoid such simple reasons. With the respect of this discussion, knowledge transfer between components can increase the distribution of views and thereby face organizations to look beyond simple causes and responses. Diversity of knowledge domain and views thus reduce the trend of organizations to concentrate the surface when trying to learn from problems.

\section{CONCLUSIONS}

Information is an essential element in the decisionmaking processes, and, from a theoretical point of view, the more useful the available information is, the easier decision making becomes. Information and Communication Technologies (ICTs), which are now commonplace in everyday activities, can generate a vast amount of information. Only a part of this information, however, is truly meaningful and useful within organizations. Data mining or information visualization techniques may solve the problem of accessing valuable data, but the application of such techniques in every possible context verges on impossible. Recently, the information technology is an important aspect of the learner's learning process. E- Learning method using the information technology impact on inevitable methods of teaching and learning process. The new trend, in the case of information technology based learning and teaching, includes: thinking, reading, listening, speaking, a useful method to effective teaching and learning, and information, communication, and computer based method using computer means and information technologies. In the proposed work, a new web based method for HPM using computers with automatically education managed components is proposed. The proposed method uses the basic HPM framework to process I/O components and different applications. The proposed method has two aspects: local education management component and global education management component. The local education management component uses the model-free computer aided learning technique to perform local education management. Moreover, global education management component interacts with the CPU processer to perform effective global education management.

\section{REFERENCES}

[1] Catino M, Patriotta G. Learning from errors: cognition, emotions and safety culture in the Italian Air Force. Organ Stud, 2013, 34(4): $37-67$.

[2] Carmeli A, Sheaffer Z. How learning leadership and organizational learning from failures enhance perceived 
organizational capacity to adapt to the task environment. JApplBehavSci 2008,44:468-89.

[3] Ron N, Lipshitz R, Popper M. How organizations learn: post-flight reviews in an F-16 fighter squadron. Organ Stud, 2006, 27(10): 69- 89.

[4] Madsen PM, Desai V. Failing to learn? The effects of failure and success on organizational learning in the global orbital launch vehicle industry AcadManage J, 2010, 53(4): 51- 76.

[5] Weick KE, Sutcliffe K. Managing the unexpected: resilient performance in an age of uncertainty. San Francisco, CA: Jossey Bass, 2007.

[6] Carmeli A, Schaubroeck J. Organisational crisis- preparedness: the importance of learning from failures. Long Range Plan, 2008, 41(1): 77-96.

[7] Hirak R, Peng AC, Carmeli A, Schaubroeck JM. Linking leader inclusiveness to work unit performance: The importance of psychological safety and learning from failures. LeadershQ, 2012, 23(10): 7 - 17.

[8] Tucker AL, Edmondson AC. Why hospitals don't learn from failures: organizational and psychological dynamics that inhibit system change. CalifManageRev, 2003, 45: 55- 72 .

[9] Edmondson AC. Learning from failure in health care: frequent opportunities, pervasive barriers. QualSaf Health Care, 2004, 13: 3-9. 